\title{
The impact of age, sex, blepharitis, rosacea and rheumatoid arthritis on Demodex mite infection
}

\author{
Aleksandra Sędzikowska ${ }^{1}$, Maciej Osęka², Piotr Skopiński
}

\author{
${ }^{1}$ Department of General Biology and Parasitology, Medical University of Warsaw, \\ Warsaw, Poland \\ ${ }^{2}$ Ofta Ltd., Warsaw, Poland \\ ${ }^{3}$ Department of Histology and Embryology, Biostructure Center, Medical University \\ of Warsaw, Warsaw, Poland
}

Submitted: 24 June 2015

Accepted: 13 September 2015

Arch Med Sci 2018; 14, 2: 353-356

DOI: $10.5114 /$ aoms.2016.60663

Copyright @ 2016 Termedia \& Banach

\author{
Corresponding author: \\ Aleksandra Sędzikowska \\ Department \\ of General Biology \\ and Parasitology \\ Medical University \\ of Warsaw \\ 5 Chalubinskiego St \\ 02-004 Warsaw, Poland \\ Phone: +48226212607 \\ E-mail: aleksandra. \\ sedzikowska@wum.edu.pl
}

\begin{abstract}
Introduction: Two human-specific Demodex species have been described: Demodex folliculorum and Demodex brevis. A medical condition caused by the presence of Demodex is called demodicosis.

Material and methods: The study material comprised eyelashes collected from 1499 patients.

Results: Demodex sp. infection was revealed in $47 \%$ of patients (487 women and 216 men). We determined the following rates of infection by age groups: $1-25$ ( $8 \%$ of infected subjects), 26-40 (36\%), 41-55 (50\%), 56-70 $(67 \%)$, over $70(77 \%)$. The sex of the subjects was not identified as a factor conducive to infection $(p=0.108)$, while their age was positively correlated with the risk of infection $(p<0.005)$. The 1499 study subjects included patients with blepharitis, rosacea, and rheumatoid arthritis. The study investigated the extent to which the above-mentioned conditions affect the risk of Demodex infection. Applying the method of logistic regression, the infection probability was estimated, depending on the age, sex, and comorbidities such as blepharitis, rosacea, and rheumatoid arthritis. Patients suffering from blepharitis were found to have a nearly 2.5 -fold higher risk of Demodex infection than those without blepharitis, and the risk for rosacea patients was determined as three-fold higher than that of the general population.

Conclusions: Blepharitis and rosacea are risk factors for Demodex infection.
\end{abstract}

Key words: demodicosis, risk factor, epidemiology.

\section{Introduction}

The Demodicidae family includes strictly specialized parasitic mites living in the skin, hair follicles or outer epidermal layers. Demodex mites show strong species specificity. Therefore, each animal species hosting these parasitic mites has an individual Demodex species typical of itself. Up to now, two Demodex species have been described which are specific for humans: Demodex folliculorum and Demodex brevis. The parasites feed on lipids and sebum [1]. One hair follicle can be inhabited by up to 25 animals oriented towards the inside of the hair follicle [2]. Demodex infection occurs mainly in elderly people; in children, the parasites occur very rarely, usually in suppressed immunity conditions [3-5]. A medical condition caused by the presence of Demodex is called demodicosis. Presently, two forms of demodicosis are known: cutaneous and ocular. 
Cutaneous demodicosis manifests itself mainly as rosacea and seborrhoeic dermatitis. Ocular demodicosis is connected with chronic refractory anterior blepharitis, recurrent styes, chalazion, and dry eye syndrome. It is believed that Demodex may be an etiological factor behind blepharitis [6]. Presence of the mites on the facial skin is often associated with the occurrence of rosacea [7-9]. Demodex mite infection may be different in different populations and ethnic groups. Regardless of the differences in Demodex prevalence, the tendency is mostly the same: the infection rate increases with patient's age. However, it is difficult to determine the role of environmental factors in Demodex infection, which demonstrates the need for further studies.

Demodex mites can be detected by standardized skin surface biopsy (SSSB), molecular techniques or direct microscopic examination. The SSSB method involves collection of the pilosebaceous follicle content using a drop of cyanoacrylic adhesive $[10,11]$. This method is used by dermatologists to identify Demodex density on the skin. Molecular techniques such as polymerase chain reaction ( $P C R)$ meanwhile are used to define the precise molecular population [12, 13]. Direct microscopic examination is a common method to detect Demodex mites in eyelashes. The result is obtained in a short time and costs are low, which is important in population studies.

The aim of this study was to examine which factors (age, sex, blepharitis, rosacea, rheumatoid arthritis) may increase the probability of Demodex mite infection. Demodex infections are very common but still little is known about the risk factors.

\section{Material and methods}

The study material comprised eyelashes from 1499 persons: patients of ophthalmology clinics and hospitals in Warsaw, who were suspected of Demodex infection (Bioethics Committee number $\mathrm{KB} / 3 / 2007)$. Four eyelashes were collected from each eye, by means of tweezers. After collection, the eyelashes were placed on a slide, soaked with a drop of Hoyer's solution [14] and examined under 20-40× magnification. A positive result was recorded, where adult mites, larvae or eggs of Demodex sp. were detected in the study material.

\section{Statistical analysis}

Statistical analysis of the obtained results was performed using SPSS Statistics software (version 19). The $t$ test was applied to compare two study groups. The probability of $p<0.05$ was considered significant and the probability of $p<0.005$ highly significant. Logistic regression and the odds ratio $(\mathrm{OR})$ were used to examine the impact of different factors on the risk of infection.

\section{Results}

We estimated the probability of Demodex infection in groups with various diseases by logistic regression. This method helped to estimate event probability (i.e. infection - dependent variable) depending on different factors, such as age, sex, blepharitis, rosacea and RA (independent variables). The results are presented in Table I. The predictive accuracy of the logistic regression model was evaluated. The logistic regression model fit the data very well: classification accuracy went up from $52 \%$ to $74 \%$.

Apart from the level of significance calculated for each factor, the odds ratio was also determined with reference to each of the factors. An odds ratio is a measure of association between an outcome such as disease in relation to an exposure such as a risk factor. The OR represents the odds that

Table I. Number, sex and mean age of non-infected and infected patients, significance and odds ratio for individual factors

\begin{tabular}{|c|c|c|c|c|c|}
\hline Factor & Number & Non-infected/mean age & Infected/mean age & Significance & OR \\
\hline Age & $\begin{array}{l}1499 \text { patients } \\
\text { (965 women, } \\
534 \text { men) }\end{array}$ & $\begin{array}{c}\text { 53\%: } 796 \text { patients } \\
\text { (478 women/41 years old, } \\
318 \text { men/32 years old) }\end{array}$ & $\begin{array}{c}\text { 47\%: } 703 \text { patients } \\
\text { (487 women/64 years old, } \\
216 \text { men/59 years old) }\end{array}$ & $p<0.005$ & 1.054 \\
\hline Gender & $\begin{array}{l}1499 \text { patients } \\
\text { (965 women, } \\
534 \text { men) }\end{array}$ & $\begin{array}{c}\text { 53\%: } 796 \text { patients } \\
\text { (478 women/41 years old, } \\
318 \text { men/32 years old) }\end{array}$ & $\begin{array}{c}\text { 47\%: } 703 \text { patients } \\
\text { (487 women/64 years old, } \\
216 \text { men/59 years old) }\end{array}$ & 0.108 & 0.790 \\
\hline Blepharitis & $\begin{array}{l}134 \text { patients } \\
\text { (86 women, } \\
48 \text { men) }\end{array}$ & $\begin{array}{c}\text { 24\%: } 32 \text { patients } \\
\text { (21 women/55 years old, } \\
11 \text { men/56 years old) }\end{array}$ & $\begin{array}{c}76 \%: 102 \text { patients } \\
\text { (65 women/64 years old } \\
37 \text { men/63 years old }\end{array}$ & $p<0.005$ & 2.475 \\
\hline Rosacea & $\begin{array}{l}67 \text { patients } \\
\text { (50 women, } \\
17 \text { men) }\end{array}$ & $\begin{array}{c}\text { 33\%: } 22 \text { patients } \\
\text { (18 women/53 years old, } \\
4 \text { men/50 years old) }\end{array}$ & $\begin{array}{c}\text { 67\%: } 45 \text { patients } \\
\text { (32 women/53 years old, } \\
13 \text { men/63 years old) }\end{array}$ & $p<0.005$ & 3.009 \\
\hline $\begin{array}{l}\text { Rheumatoid } \\
\text { arthritis }\end{array}$ & $\begin{array}{l}69 \text { patients } \\
\text { (58 women, } \\
11 \text { men) }\end{array}$ & $\begin{array}{c}\text { 67\%: } 48 \text { patients } \\
\text { (39 women/56 years old, } \\
7 \text { men/62 years old) }\end{array}$ & $\begin{array}{c}\text { 33\%: } 23 \text { patients } \\
\text { (19 women/68 years old, } \\
4 \text { men/63 years old) }\end{array}$ & 0.054 & 0.570 \\
\hline
\end{tabular}


an outcome will occur given a particular exposure, compared to the odds of the outcome occurring in the absence of that exposure [15]. The results are presented in Table I (interpretation of these results in discussion).

Study subjects were divided into 5 age groups, with the percentage of infected patients, broken down into age subgroups, presented in Figure 1.

\section{Discussion}

Based on the performed analyses, it was determined that sex has no impact on Demodex infection, being a statistically negligible factor $(p>0.05)$. Thus, one can conclude that the probability of Demodex infection is comparable for women and men alike. Similar results were obtained by Aycan et al., who did not find sex to be a significant factor conducive to infection with Demodex sp. either [16].

Correct diagnosis is important as demodicosis may be misdiagnosed as an allergic inflammation or bacterial or fungal infection. Demodex mite infection is very common, and the prevalence can reach $100 \%$ of the older population [17]. All of the Demodex-positive patients were further divided into age subgroups. In order to investigate the potential interdependence between the subjects' age and probability of infection, the method of logistic regression was applied. It was examined how the age (independent variable) affects the presence of Demodex sp. (dependent variable). The analyses indicated that the age-infection probability dependence was highly statistically significant $(p<0.005)$. The logistic regression model confirms that patient age is positively correlated with the risk of infection, but the impact is slight $(O R=1.054)$ in that it is noticeable, but at several-year intervals rather than year on year. Therefore, the older the patient, the more probable it is that they are infected with Demodex (Figure 1). A similar dependence, i.e. the risk of infection growing with age, has been described by other authors $[18,19]$. However, not all of the authors have reached the same conclusions. Dhingra et al. believe that the rate of Demodex infection is highest in the 20 to 40 age bracket, which is purportedly related to increased sebum secretion [20]. On the other hand, Zhao et al. found that Demodex mite infection rates increased in the 12-30-year-old patients, and remained stable amongst the older patients [21].

Patients with blepharitis or rosacea and immune-compromised ones (in this case RA patients on immunosuppressive drugs) were selected from among all the study subjects. In order to determine the dependence between a given condition and the risk of Demodex infection, the logistic regression method was applied. As was the case

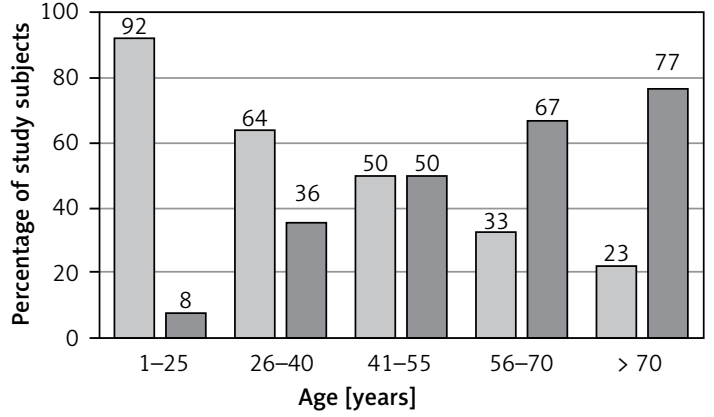

$\square$ Non-infected subjects $\quad \square$ Infected subjects

Figure 1. All study subjects divided into age subgroups

with the previous calculations, the presence of Demodex mites was the dependent variable. Based on the performed analysis, it was observed that two out of the three above-mentioned conditions were positively correlated with the risk of infection. Indeed, for blepharitis and rosacea the correlation was highly statistically significant $(p<0.005)$.

In the case of the blepharitis patients, the odds ratio was 2.475 . It means that for the blepharitis patients the risk of Demodex infection is nearly 2.5-fold higher than for those who do not suffer from blepharitis. In the case of rosacea, $O R=3.009$, i.e. the rosacea patients suffer a 3-fold higher risk of infection with Demodex sp. as compared to people who are not affected by rosacea. On the other hand, RA and RA-related immunosuppressive treatment was not found to have any significant impact on the probability of Demodex infection $(p>0.05)$. Ciftci et al. obtained similar results - the incidence and density of $D$. folliculorum in patients with RA were not significantly different from those of controls [22].

Demodex may be an etiological factor for blepharitis and rosacea, so the impact of those diseases was studied. However, the relevance of Demodex spp. in blepharitis remains controversial [6]. In the case of cutaneous demodicosis the presence of 5 or more Demodex on $1 \mathrm{~cm}^{2}$ will significantly increase the risk of cutaneous demodicosis [23]. There is a possibility that Demodex mite infection may result in blepharitis, but it is not the only cause; not all patients with blepharitis were infected ( $76 \%$ of patients).

Demodicosis is a major medical problem in dermatology and ophthalmology because of the chronic character of the disease. Demodex mites may cause ocular demodicosis with symptoms such as burning and itching of eyelids. There are difficulties in early diagnosis, and consequences of using inappropriate drugs, e.g. steroids. The treatment of demodicosis is difficult and may last for several months. Good efficacy of tea tree oil against Demodex sp. has been reported [24] and 
other essential oils, for example salvia and peppermint [25].

\section{Conflict of interest}

The authors declare no conflict of interest.

\section{References}

1. Desch C, Nutting WB. Demodex folliculorum (Simons) and $D$. brevis Akbulatova of man: redescription and reevaluation. J Parasitol 1972; 58: 169-77.

2. Coston TO. Demodex folliculorum blepharitis. Trans Am Ophthalmol Soc 1967; 65: 361-92.

3. Ivy SP, Mackall CL, Gore L, Gress RE, Hartley AH. Demodicidosis in childhood acute lymphoblastic leukemia: an opportunistic infection occurring with immunosuppression. J Pediatr 1995; 127: 751-4.

4. Patrizi A, Neri I, Chieregato C, Misciali M. Demodicidosis in immunocompetent young children: report of eight cases. Dermatology 1997; 195: 239-42.

5. Herron MD, O'Reilly MA, Vanderhooft SL. Refractory Demodex folliculitis in five children with acute lymphoblastic leukemia. Pediatr Dermatol 2005; 22: 407-11.

6. Wesolowska M, Knysz B, Reich A, et al. Prevalence of Demodex spp. in eyelash follicles in different populations. Arch Med Sci 2014; 10: 319-24.

7. Roihu T, Kariniemi AL. Demodex mites in acne rosacea. J Cutan Pathol 1998; 2: 550-2.

8. El-Shazly AM, Ghaneum BM, Morsy TA, Aaty HE. The pathogenesis of Demodex folliculorum (hair follicular mites) in females with and without rosacea. J Egypt Soc Parasitol 2001; 31: 867-75.

9. Chen W, Plewig G. Are demodex mites principal, conspirator, accomplice, witness or bystander in the cause of rosacea? Am J Clin Dermatol 2015; 16: 67-72.

10. Forton F, Song M. Limitations of standardized skin surface biopsy in measurement of the density of Demodex folliculorum. A case report. Br J Dermatol 1998; 139: 697-700.

11. Aşkin U, Seçkin D. Comparison of the two techniques for measurement of the density of Demodex folliculorum: standardized skin surface biopsy and direct microscopic examination. Br J Dermatol 2010; 162: 1124-6.

12. de Rojas M, Riazzo C, Callejón R, Guevara D, Cutillas C. Morphobiometrical and molecular study of two populations of Demodex folliculorum from humans. Parasitol Res 2012; 110: 227-33.

13. Zhao YE, Ma JX, Hu L, Wu LP, De Rojas M. Discrimination between Demodex folliculorum (Acari: Demodicidae) isolates from China and Spain based on mitochondrial cox1 sequences. J Zhejiang Univ Sci B 2013; 14: 829-36.

14. Criado-Fornelio A, Heredero-Bermejo I, Pérez-Serrano J. Alternative mounting media for preservation of some protozoa. J Microbiol Methods 2014; 105: 146-9.

15. Szumilas M. Explaining odds ratios. J Can Acad Child Adolesc Psychiatry 2010; 19: 227-9.

16. Aycan OM, Otlu GH, Karaman U, Daldal N, Atambay M. Frequency of the appearance of Demodex sp. in various patient and age groups. Turkiye Parazitol Derg 2007; 31: 115-8.

17. Liu J, Sheha H, Tseng SC. Pathogenic role of Demodex mites in blepharitis. Curr Opin Allergy Clin Immunol 2010; 10: 505-10.

18. Lee SH, Chun YS, Kim JH, Kim ES, Kim JC. The relationship between Demodex and ocular discomfort. Invest Ophthalmol Vis Sci 2010; 51: 2906-11.
19. Lacey N, Kavanagh K, Tseng SC. Under the lash: Demodex mites in human diseases. Biochem (Lond) 2009; 31 $2-6$.

20. Dhingra KK, Saroha V, Gupta P, Khurana N. Demodex-associated dermatologic conditions - a coincidence or an etiological correlate. Review with a report of a rare case of sebaceous adenoma. Pathol Res Pract 2009; 205: 423-6.

21. Zhao YE, Peng Y, Wang XL, et al. Facial dermatosis associated with Demodex: a case-control study. J Zhejiang Univ Sci B 2011; 12: 1008-15.

22. Ciftci IH, Dundar U, Cetinkaya Z, et al. Demodex folliculorum in patients with rheumatoid arthritis. Acta Parasitol 2007; 52: 70-3.

23. Forton F, Seys B. Density of Demodex folliculorum in rosacea: a case-control study using standardized skin-surface biopsy. Br J Dermatol 1993; 128: 650-9.

24. Gao YY, Xu DL, Huang IJ, Wang R, Tseng SC. Treatment of ocular itching associated with ocular demodicosis by 5\% tea tree oil ointment. Cornea 2012; 31: 14-7.

25. Sędzikowska A, Osęka M, Roman B, Jaremko E. Impact of Salvia and peppermint oil on the in vitro survival of Demodex mites. J Bacteriol Parasitol 2015; 6: 1-2. 